\title{
Deprivation of Media Attention by Fukushima Daiichi Nuclear Accident: Comparison Between National and Local Newspapers
}

\author{
Ryuma Shineha and Mikihito Tanaka
}

\begin{abstract}
On March 11th in 2011, a huge earthquake and tsunami struck Japan and caused severe accidents at the Fukushima first nuclear power plant (NPP). The impact and damages of these triple disasters, called " 3.11 ," continue to this day. There was a diversity of damages and social conditions among devastated areas. This means that this disaster struck so broad area that it brought many kinds of "realities" to different areas. Therefore, we cannot treat the various regions that were affected uniformly. At the same time, the attention given to the 3.11 based on location has ultimately been covered differently between various media sources. The aim of this paper is to share basic descriptions and media analysis of the 3.11 disasters for future discussions. Through our analysis, it is showed that there is a different framing of the 3.11 between national and local media. The difference implicates that it is deprived of social interest in the national newspaper by the NPP accident, and on the other hand, the local newspaper kept their perspectives reflecting damages from the earthquake and tsunami.
\end{abstract}

Keywords $3.11 \cdot$ Media analysis $\cdot$ Newspaper $\cdot$ Local media

\section{Introduction}

On March 11th in 2011, a huge earthquake and tsunami struck Japan and resulted in many victims. The earthquake and tsunami caused severe accidents at the Fukushima first nuclear power plant (NPP). The impact and damages of these triple disasters, called "Higashi-Nihon-Daishinsai" or "3.11," continue to this day.

\footnotetext{
R. Shineha $(\bowtie)$

Seijo University, Tokyo, Japan

e-mail: r_shineha@seijo.ac.jp

M. Tanaka

Waseda University, Tokyo, Japan

e-mail: steman@waseda.jp

(C) The Author(s) 2017

J. Ahn et al. (eds.), Resilience: A New Paradigm of Nuclear Safety,

DOI 10.1007/978-3-319-58768-4_9
} 
To consider various issues resulting from the 3.11 disasters, we must understand the continuing damages, social-structural issues behind the 3.11, and the complex effects of triple disasters. In addition, how "realities" of damaged sites were overlooked in the society is another important point. This is rephrased to, "how were social attentions deprived?" In response to this question, we conducted quantitative media analysis between national and local newspapers: Asahi-shimbun and Kahoku-shimpo.

\subsection{Basic Description of the 3.11 Disasters}

The aim of this section is to share basic descriptions of the 3.11 triple disasters. For this purpose, we would like to use a description-oriented method. Through descriptions of damaged sites, we will know the complexity of damages brought by the earthquake, tsunami, and the NPP accident.

For the horrible triple disasters, there were over 20,000 deaths and missing persons. Approximately 170,000 people evacuated from their homes in Japan. Three prefectures in particular-Miyagi, Iwate, and Fukushima - were the most affected (for example, deaths in the Miyagi prefecture reached over 10,000). We summarize the number of victims, focusing on these three prefectures, in Table $1 .{ }^{1}$ The tsunami wiped out several hundred kilometers of coastline in towns. Concerning causes of death, drowning was responsible for over $90 \%$ of lost victims, and about $65 \%$ of the victims were over the age of 60 [3].

Looking at the press release by the national government on June 24, 2011, it was estimated that total losses for the building, life-line, social infrastructure, agriculture, and others reached approximately 16.9 trillion yen. Over 25 million tons of rubble and general waste were generated. Of course, there continues to be other serious problems, such as the stress of disaster victims, discrimination, etc.

In addition, the social conditions were different between damaged areas. Previous studies showed that local towns that were seriously injured were considered to be an aging society, farming and fisheries society, and generally poorer than when compared to metropolitan society $[1,2]$. And of course, such negative conditions compound upon each other. Generally speaking, the municipalities that were seriously injured faced deeply-indented coastlines; this geographical disadvantage is not only vulnerable to tsunamis but also reinforced aging and economically vulnerable society. Furthermore, these vulnerabilities (such as an aging

\footnotetext{
${ }^{1}$ Previous data of the Table 1 were represented in Shineha [1] and Tanaka et al. [2]. This data is updated, using statistics published by governments until May 8th 2015: Prefectural governments of Miyagi, Iwate, Fukushima, and the Reconstruction Agency. Concerning the death toll, the associated number of deaths from the 3.11 was included. In addition, the number of the disappeared is the number of those who never received death notifications of their family members. There are 224 persons who were registered in this type of situation.
} 
Table 1 Breakdown of damages

\begin{tabular}{l|l|l|l|l}
\hline & & Iwate & Miyagi & Fukushima \\
\hline \multirow{2}{*}{ Human damages } & Fatalities & 5,124 & 10,534 & 3,727 \\
\cline { 2 - 5 } & Missing & 1,129 & 1,246 & 3 \\
\cline { 2 - 5 } & $\begin{array}{l}\text { Evacuees (to other } \\
\text { Prefecture) }\end{array}$ & 28,242 & 67,510 & 69,208 \\
& $(1557)$ & $(7055)$ & $(46,170)$ \\
\hline $\begin{array}{l}\text { Collapse of } \\
\text { buildings/houses }\end{array}$ & $\begin{array}{l}\text { Complete or half } \\
\text { destroyed) }\end{array}$ & 26,163 & 238,123 & 92,905 \\
\hline
\end{tabular}

society) have been reinforced more and more in some areas of damaged sites after the 3.11 .

In addition to the terrible natural disasters, we also faced the severe accident of NPPs. In "Risk Society," Ulrich Beck discussed the globalization of risk and inequality on the distribution of risk and benefit [4]. Such discussions regarding risk society point out a collision of risk receiver and benefit receiver as well as risk gap according to social stratum and area. Generally speaking, the weak members of society tend to become risk receivers. ${ }^{2}$

\subsection{The Effect of the Fukushima-Daiichi Nuclear Power Plant Accident}

In addition to the huge damage of the earthquake and tsunami, evacuation zones were set up after the NPP accident and many people were forced to leave their towns, particularly in the Futaba area of the Fukushima prefecture. At the first, the evacuation zone was set within a radius of $20 \mathrm{~km}$ from the NPP. However, after April 1, 2013, the evacuation zone was redefined in three categories according to the amount of radiation: Difficult-to-return zone (Kitaku-Konnan Kuiki); No-residence zone (Kyojyu-Seigen Kuiki); and zone being prepared for lifting of evacuation order (Hinan-Shiji Kaijo Junbi Kuiki). ${ }^{3}$

Figure 1 shows the current situation of Namie, a town that was established as a mandatory evacuation zone after the NPP accidents. However, after the re-categorization of evacuation areas on April 1, 2013, a part of Namie became available for short-time stays with the local government's permission. At the current status, Namie has three different types of evacuation areas.

\footnotetext{
${ }^{2}$ In a model of disaster studies, disaster is regarded as an opportunity in which social vulnerability comes up to the surface [5]. Thus, when we think disaster and its hazard, we also have to think about the social structure and vulnerability behind the disaster.

${ }^{3}$ Since the 1st April 2016, zone being prepared for lifting of evacuation order (Hinan-Shiji Kaijo Junbi Kuiki) was opened. As the result, the center of the town can be accessed without permission.
} 

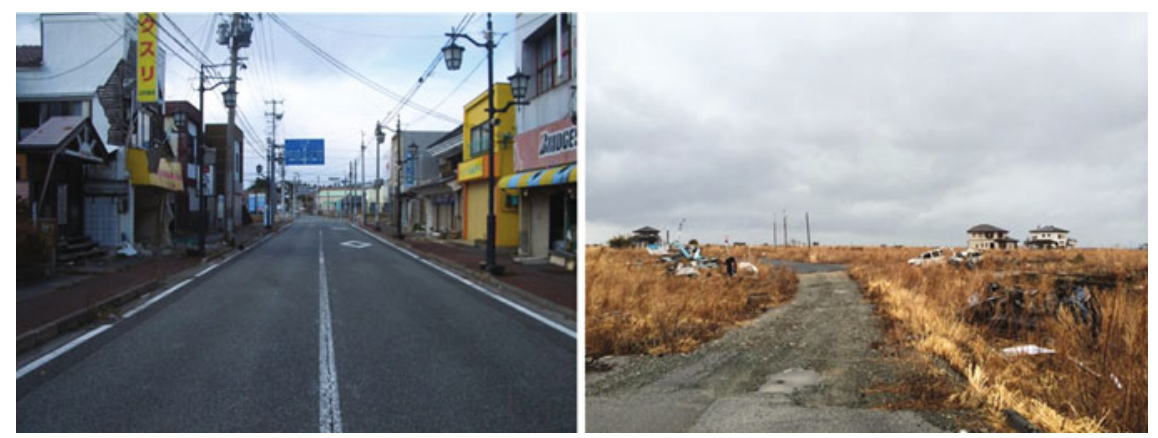

Fig. 1 The town Namie collapsed by earthquake and tsunami. Left Main street of the town (April 11th, 2013). Right The seaside area (Uketo area; March 2nd, 2014). They show the effects of isolation from the NPP accident

At the time of taking these pictures on April 11, 2013, destroyed houses were left as-is for more than 2 years after the NPP accident. In Namie, there were many houses and buildings destroyed by the earthquake. The level of collapse has progressed according to time. The inside walls became moldy and eventually collapsed, because rains invaded through the holes of damaged ceilings. There are few figures in the street.

In addition, the coastal area was devastated by the tsunami. The horrible destruction and traces of the tsunami were left as-is for more than 4 years. In other areas, removing of houses, cars, and ships destroyed by the tsunami has been developed. However, in the coastal area of Namie, those remained for more than 4 years, because of the recovery and reconstruction process, which was prevented, and continued the isolation from the NPP accident. As a result, the level of damage varied among the affected regions and still remains.

The continuous problems of these affected situations make it difficult for residents to come back. According to the current report of a questionnaire conducted by the research group of Waseda University collaborated with Namie local office, the answer of "I will not come back to Namie" (34.8\%) and "I don't know" (45.6\%) were most chosen responses. On the other hand, the answer related to "I will come back" constituted just $17.0 \%$ of responses. ${ }^{4}$ The popular reason given for why they will not come back was, "if we come back, it's difficult (or impossible) to live as we used to" [6].

Over 4 years have already passed since the 3.11. Some evacuees succeeded in making new lives in other areas. The relationship between their children and friends are also points of consideration to stay there. Moreover, if they come back to Namie in its current state, serious damages in terms of infrastructure, community, and

\footnotetext{
${ }^{4}$ Total score of "I will come back to the Namie after the completion of de-contamination process by the national government" and "I would like to come back to the Namie if de-contamination process takes a long time."
} 
various capitals (cultural, social, economic, and human) have still not been recovered. Although the Namie local office planned for the returning process to start from 2017, many issues and hurdles remains. Officers recognize their difficult tasks still ahead. When we think of the effects of the NPP accident, we should consider the complex influences of the NPP accident on the reconstruction process.

\subsection{The 3.11 and Information Ecology}

Keeping in mind the variety of continued damages and issues described above, we should start to consider problems of social structure behind the 3.11 from the viewpoints of "information" and "media." Huge amounts of information and discourses concerning the 3.11 have persisted, and in our opinion, this is one of the most significant features of the 3.11 .

We surmise that many readers can imagine the effect of the Internet and social network sites (SNSs) in the 3.11 contexts. Actually, the spread of information via the Internet enables us to create and use large amounts of information. This situation has been reinforced by SNSs such as Twitter, Facebook, and so on. These convenient informational tools set the base of information for volunteers in a disaster.

However, we should take a point of view that there is an information gap according to social stratum, income, age, etc. Looking at the status of Japanese Internet usage just before the 3.11, the reports published by the Ministry of Internal Affairs and Communications (MIC) in 2011, we can extract three important aspects:

- Generally speaking, the coefficient of use of Internet for elderly people is lower than for younger people (e.g., 60-64 age, 70.1\%; 65-69 age, 57.0\%; 70-79, $39.2 \%$; over $80,20.3 \%$ ).

- Families with low annual incomes have a low coefficient of use of Internet (e.g., under 2 million, $63.1 \%$; 2 million to 4 million, 68.6\%; over 6 million, over $80 \%)$.

- Use of Internet depends on the geographical area. The Tohoku region has a low score compared to other metropolitan areas.

When we think of 3.11, we should take such conditions of the Japanese information society into account, in addition to destruction of information infrastructure. Generally, the damaged areas from 3.11 are aging and low income communities. Moreover, in the 1970s, Japanese society attempted to be a society where "all of the citizens are middleclass." As a result, many upper-middleclass people appeared. However, looking at the media usage, the relationship between social class and usage and thoughts regarding media has been discussed and investigated since the 2000s. Several gaps according to social stratum have been recognized, such as the term "digital divide." For example, lower social capital cultures use mobile phones 
but not smartphones; they are social gamers but do not have PCs; and they are light Internet users. Another example is that TV audiences are part-time workers. On the other hand, higher social capital clusters have smartphones, they are users of tablet PC and SNSs, and so on. In summary, current gaps of information and media usage have appeared.

In any event, it seems that the majority of Internet users regarding the 3.11 were in the non-damaged metropolitan areas such as Tokyo, Yokohama, etc. For the gap of information environment, victims could not collect and transmit information effectively, compared to a majority in the information society. It seems that this "gap of information environment" is one of the background factors for the gap of "information, which is focused and taken up by and in media."

Considering this situation, we should review different information sources used in local sites to understand "realities" of information ecology of the 3.11. Rausch discussed the particular and significant role of local newspapers in local society in Japan [7]. Also, in damaged areas of the 3.11, they have their key local newspapers. Thus, we have to focus on the contents and framings of local newspapers in addition to national-level media. From the point of view that media have played various roles in agenda-building and bringing attention to issues through framing [8-11], analysis of news media should be conducted. What was the focus in national and local newspapers? What kinds of differences existed between national and local newspapers in the 3.11 context? To answer these questions, we conducted comparative quantitative analysis of Asahi-shimbun and Kahoku-shimpo.

\section{Materials and Methods}

\subsection{Data Collection of National and Local Newspapers}

In this chapter, we focus on the Asahi-shimbun as an example of a national newspaper, and also Kahoku-shimpo as an example of a local newspaper. Asahishimbun is one of the famous national newspapers of Japan. News articles of Asahishimbun were collected from the database KikuzoII. Kahoku-shimpo is the most famous local newspaper, which has top share in the Miyagi Prefecture. Text data of Kahoku-shimpo were collected from the Kahoku-shimpo database. As for the results, we collected 5,405 articles of Asahi-shimbun from March 11 to April 7. Concerning Kahoku-shimpo, 2,049 articles from March 12 to April 8, 2011 were collected. ${ }^{5}$

\footnotetext{
${ }^{5}$ Straight news from news service companies were excluded from the Kahoku-shimpo data set. In addition, at the first several days, "Kanto-Tohoku Great Earthquake" was used in Kahoku-shimpo, and these words were replaced with "Higashi-Nihon Daishinsai" in this analysis.
} 


\subsection{Seeking Specific Keywords and Co-word Mapping Comparison Between National and Local Newspapers}

Since March 11, there has been a large amount of information while discourse related to 3.11 has been rampant. Thus, we conducted quantitative analysis of discourses regarding 3.11 in legacy and social media. We conducted frequency analysis, analysis of specific keywords of each week, and network analysis focusing on the co-occurrence of keywords (co-word).

For analysis of frequency and specific keywords ranking ${ }^{6}$ of each week, we used KH coder (http://khc.sourceforge.net/) developed by Koichi Higuchi [12, 13].

We then searched for the target keywords in each text. We employed co-word analysis to describe Japanese media trends on the 3.11. The analysis employed in the present study relied on previous research by Leydesdorff and Hellsten $[14,15]$. They expressed co-words such as "the carriers of meaning across different domains" ([15]: 232). The method of analysis here basically depended on previous studies by Leydesdorff and Hellsten [14, 15]. Salton's cosine was calculated as the similarity index [16-18]. In all analysis of this chapter, the cosine threshold was settled at 0.375. Networks have been described by Pajek [19]. For the configuration algorithm for nodes, the Kamada and Kawai algorithm was used [20]. As the index of centrality, "Betweenness centrality" was used [21].

\section{Results}

We would like to discuss another gap: "gap of information, which is focused and taken up by and in media". Figure 2 shows the time-lined change of article number and appearance ratio of keywords of Asahi-shimbun and Kahoku-Shinpo. Asahishimbun is one of the most prestigious newspapers in Japan. Kahoku-Shinpo is the most famous and important block newspaper in the Miyagi Prefecture. Looking at this line-chart of Asahi-shimbun, we analyzed the oscillation cycle of article numbers and the change of trend in keyword appearance. The appearance ratio of "Earthquake" gradually decreased, but on the other hand, the ratio of "NPP" increased. At the same time, "tsunami" marked a lower score than "NPP." Meanwhile, it is clear that Kahoku-Shinpo has different trends from Asahi-shimbun. In Kahoku-Shinpo, the appearance ratio of "tsunami" continued to remain equal to "NPP." The oscillation cycle of article number in Asahi-shimbun had the tendency to decrease, whereas, there are no such trends of decrease in article numbers in Kahoku-Shinpo.

\footnotetext{
${ }^{6}$ For making ranking of specific keywords of each time-tag, KH coder calculated Jaccard index between time-tag and keywords.
} 

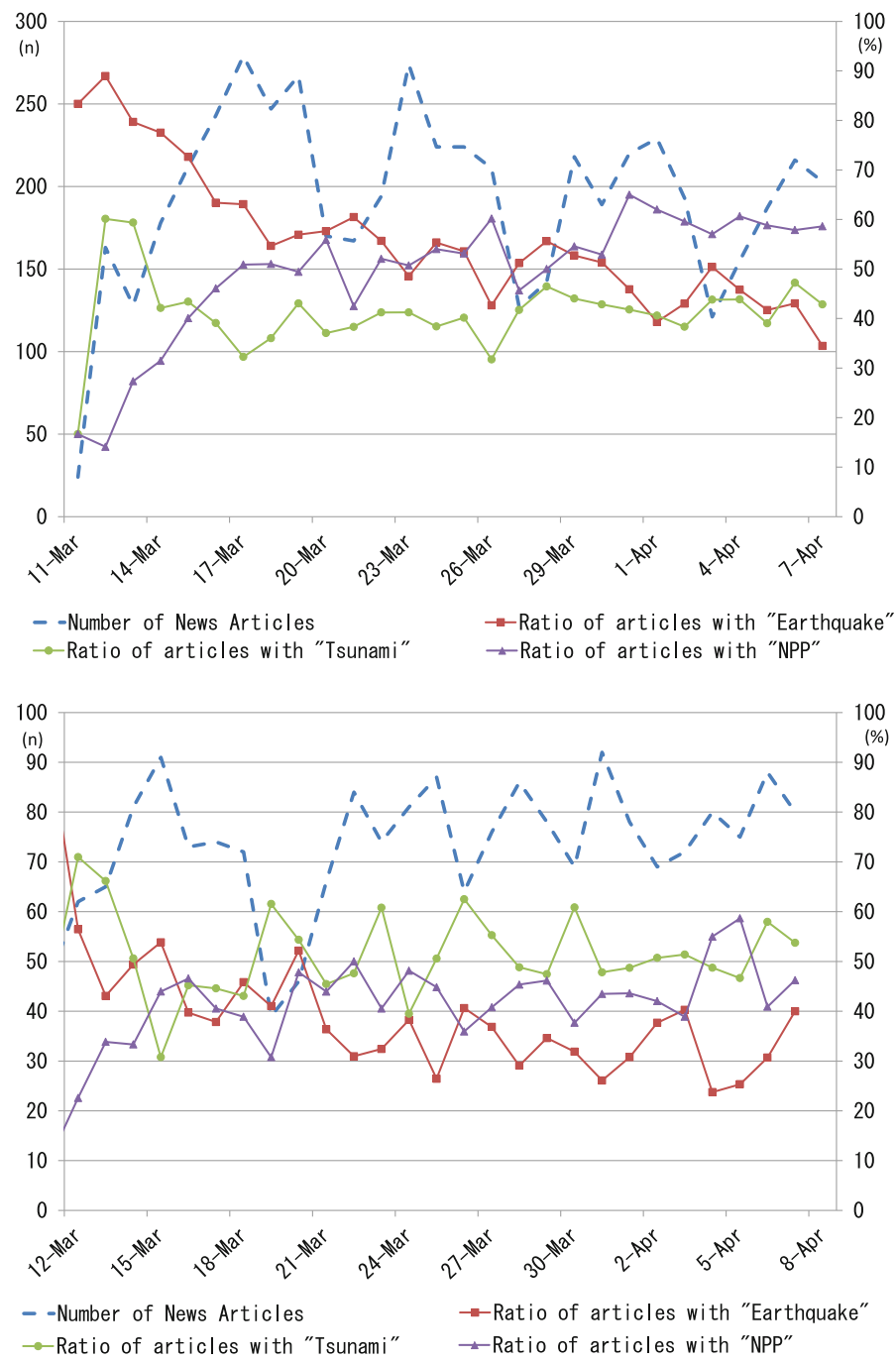

Fig. 2 Time-lined change of keywords appearance of Asahi-Shimbun and Kahoku-Shimpo during the first months. In these line charts, left axis shows the number of news articles concerning the 3.11 , right axis shows the appearance ratio of each keyword

Tables 2 and 3 show the time-lined changes of top 10 characterized keywords of Asahi-shimbun and Kahoku-Shinpo from first to fourth week. In this tables, Jaccard index of time-tag (week 1, week 2, etc.) and keywords was used. From the Table 2 of Asahi-shimbun, we can find that keywords related to earthquake and tsunami were particular in the first week. However, this situation changed after the second 


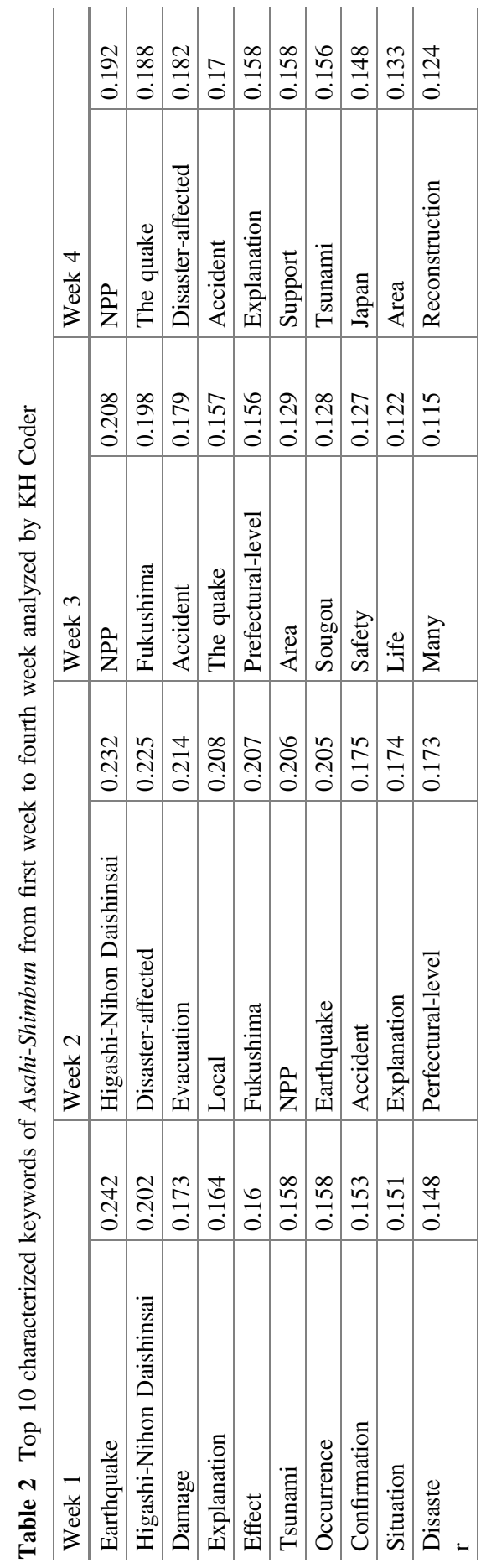




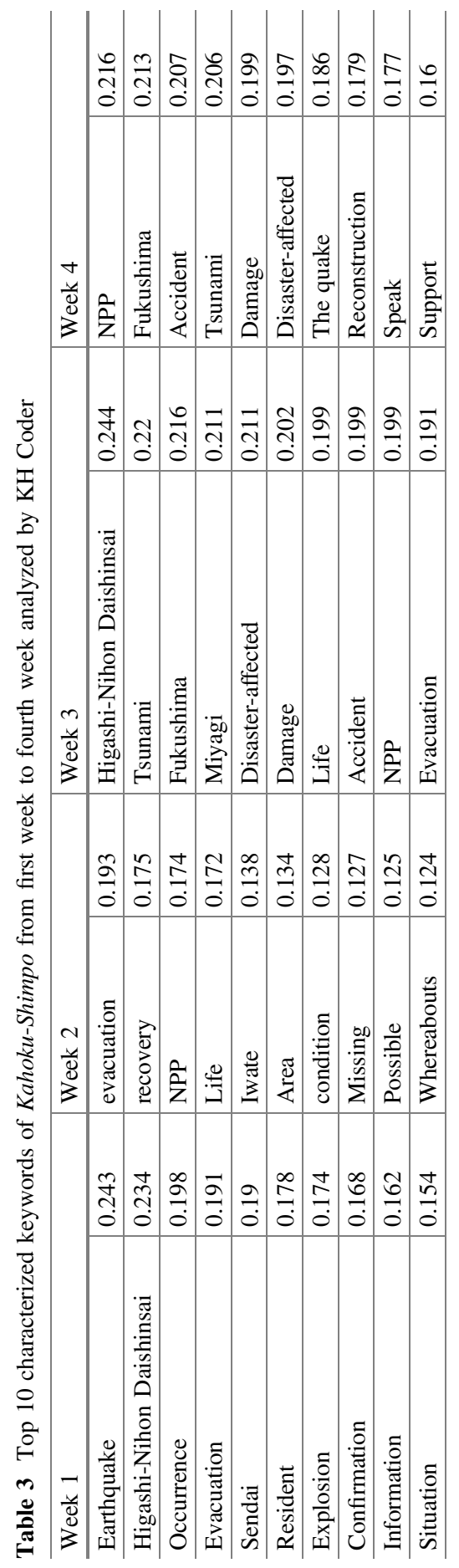



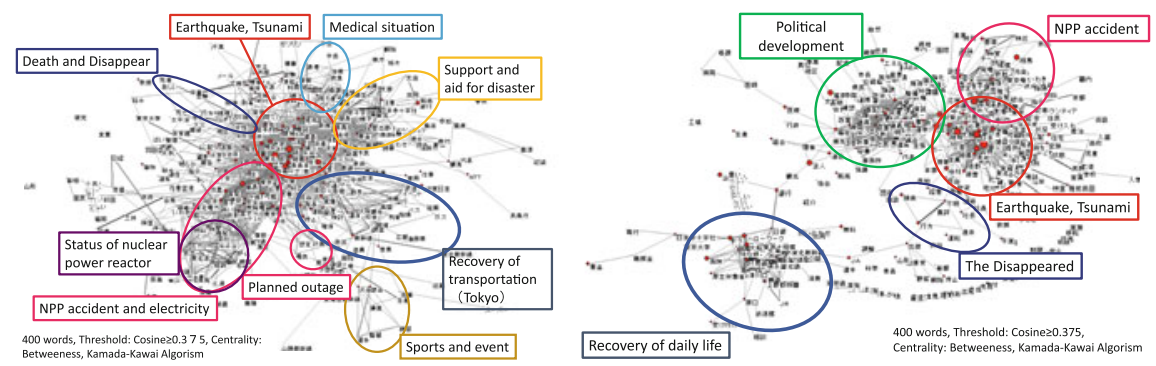

Fig. 3 Co-word map of Asahi-Shimbun (left week 1, right week 4)

week. Keywords concerning the Fukushima NPP accident appeared clearly in this ranking. This trend was strengthened according to time. On the other hand, Table 3 of Kahoku-Shinpo shows a different trend. For example, in week 2, "recovery" appears in the second position of the ranking. Simultaneously, "Iwate," "missing," and "whereabouts," are ranked. This is a different character from the results of Asahi-shimbun. Also in week 3, "tsunami" is ranked in the second position, higher than "NPP." The rank of "NPP" of Kahoku-Shinpo in week 3 is lower than the result of Asahi-shimbun.

Figure 3 describes the co-word network from March 11 to March 17 (first week after the 3.11), and from April 1 to April 7 (fourth week after the 3.11) of Asahishimbun. Clearly, we can find the difference of network structure among two co-word networks. This means the degree of organization of topics. The co-word network of the first week shows the confusion of topics and agendas in the aftermath. The organization of topics and agendas progressed according to time (see Fig. 3). Furthermore, we can extract more implications from these co-word networks. The keyword cluster meaning "Earthquake and Tsunami" has a dense network with keyword cluster meaning "NPP accident and electricity." This means that the topics on "Earthquake and Tsunami" and topics on "NPP accident and electricity" were often connected in articles. This trend is seen in all co-word networks of each week (data not shown).

On the other hand, Fig. 4 shows the co-word network of Kahoku-shimpo in the first (March 12-March 18) and fourth week (April 2-April 8) after the 3.11. They have some different characters from the co-word networks of Asahi-shimbun. One of the features of Kahoku-shimpo is that there are relatively weaker connections between "Earthquake and Tsunami" and "NPP accident" than others. We can find this point from the result of the first week after the 3.11. The co-word of Asahishimbun in the fourth week showed clear co-word clusters on "Political development"7 but on the other hand, "Medicine and human service" and "Support and aid for disaster" appeared in Kahoku-shimpo at that time.

\footnotetext{
${ }^{7}$ At that time, nationwide local elections were conducted, and this theme attracted interests of national media.
} 


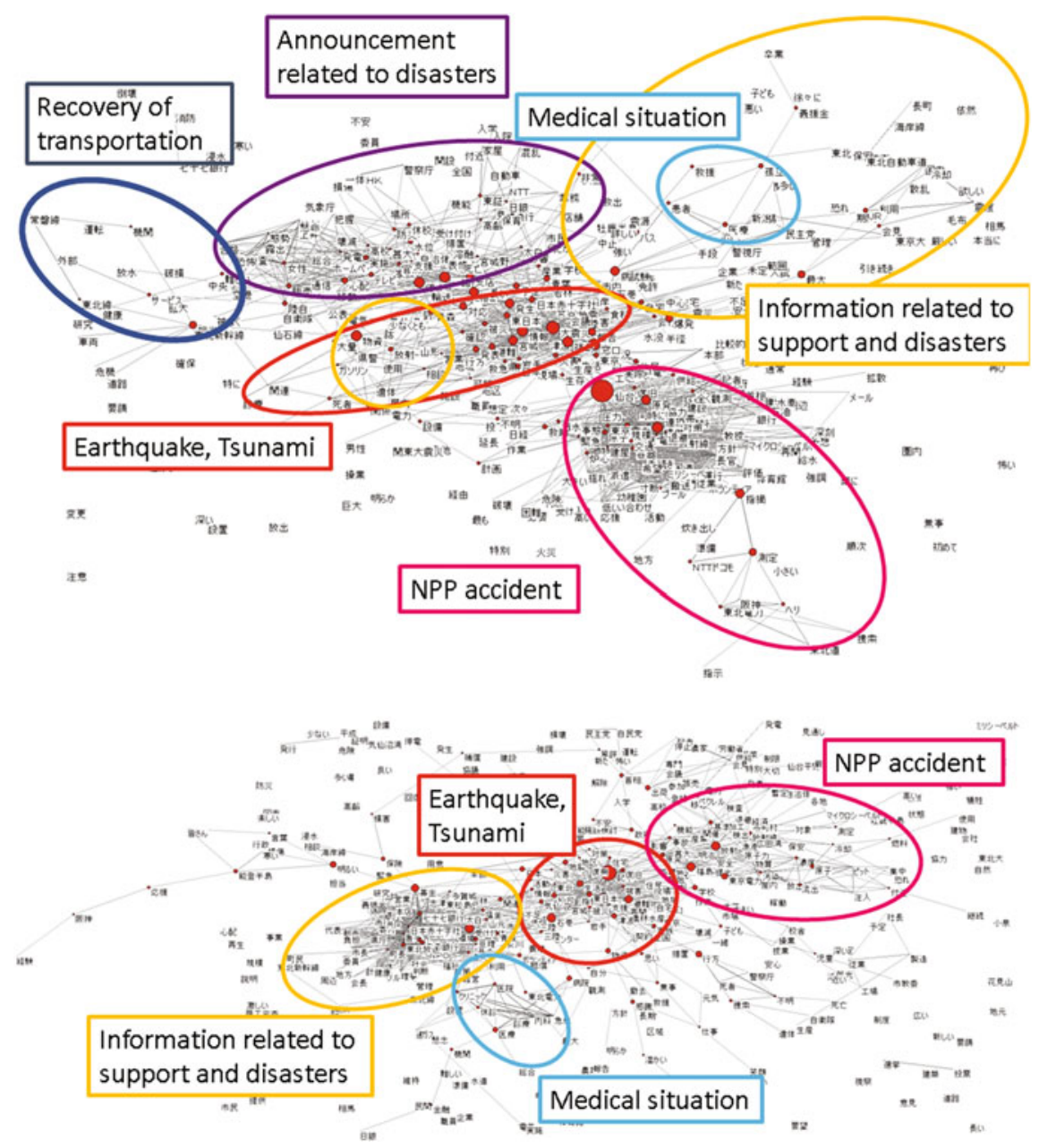

Fig. 4 Co-word map of Kahoku-Shimpo (top week 1, bottom week 4)

\section{Discussion}

Tanaka, Shineha, and Maruyama also showed that there are gaps of interests between newspapers and social media [2]. From their study, web news showed a rapid decrease in topics on the 3.11 disasters, but there were simultaneous increases in topics regarding "entertainment," "sports," "economics," and so on. Although this shift of interest is common for media, the difference of degree between media is illustrated. This result can be interpreted as newspapers continuing to take up 3.11 issues more actively than Web news and underpin public interests on the 3.11 disasters. However, we should not dismiss that topics of 3.11 in newspapers have 
also been dominated by topics regarding "NPP," and the topics of "earthquake and tsunami" were covered with them.

At the same time, blog entries with contents on "Earthquake" and "Tsunami" rapidly decreased. After the decrease of "Earthquake" and "Tsunami," "Radiation exposure" and "NPP accident" rapidly increased. However, interest on them were not sustained. In summary, interest on disasters and the NPP accident have rapidly faded out. The remained and stable interest was about "low radiation exposure" and "internal exposure." The rapid decrease of interest on NPP was also found on Twitter. In the analysis of Twitter, we categorized a variety of topics such as "NPP" such as "NPP accident," "Nuclear power policy," etc. In the aftermath of the NPP accident, tweets regarding "NPP" occupied in over $10 \%$ of all tweets, however, by the third month after the accident, the coverage decreased to fewer than $2 \%$. Shortly thereafter, in the Internet sphere, it seemed that the interest concerning the 3.11 rapidly decreased [2]. Considering insights from the report on Japanese Internet use published by the Ministry of Internal Affairs and Communications [22], there is a gap of coefficient use of Internet according to different areas affected by the disasters. The Tohoku region has a low score compared to other metropolitan areas. This indicates that the decrease of interest in the earthquake and tsunami was driven by interests of urban residents with less damages. In other words, the majority of generator and consumer of discourses concerning the 3.11 on the Internet were people in the metropolitan areas with less damages.

Simultaneously, our current data indicated that there are different media interests between national and local newspapers. The national newspaper (Asahi-shimbun) tended to focus on the NPP accident rather than tsunami and earthquake, while on the other hand, the local newspaper (Kahoku-shimpo) tried to keep their attention placed toward the tsunami and earthquake. This indicates that these two newspapers faced different contexts or "realities." However, at least, it can be said that the "NPP" accident played a strong role in setting topics and engulfed interests on "Earthquake and Tsunami" in national and social media, and the gap of interests between national and local media became broader. We should discuss the effect of the NPP accident from the perspectives of "exploitation of interests" hereafter. Considering previous discussions of media studies, it can be said that gaps of attention between national/social media and local media will influence the distribution of capital and social interests during the reconstruction process through their agenda and frame building process [9-11].

\section{Conclusion}

There are continuous damages in the sites devastated by earthquake, tsunami, and the NPP accident. Damages show their complex characters according to areas. Particularly in areas where it has been regarded as evacuation areas for the NPP accident, various effects and hurdles for the reconstruction process appeared. Therefore, we cannot treat those effects uniformly. In addition, there are different 
trends of media attention between national/social and local media. "Realities," framings, and agendas of local media of damaged sites faced difficulties to spread at the national level. Although the rapid decrease of interest concerning 3.11 occurred in national and social media, local media continued to face their "realities" at each site.

The disaster strucked local sites but the discussion of the reconstruction process related to national level regulations. During dialogues with local journalists conducted by our research group, they said that they felt weak to set the agenda process at the national level. Briefly, the locals were "peripheralized" and agenda-setting was developed in the "center" without enough care for local contexts and diversity of "realities." While the situation continues, the gap of reconstructions has been spread gradually according to gaps of damages and social conditions of areas. However, attention continues to decrease.

Acknowledgements Authors were supported by grant-in-aid of SOKENDAI-CPIS, Seijo University (Tokubetsu-Kenkyu-Joseikin), Suntory Foundation, and the JSSTS-Kakiuchi-Kinen Support Award 2014.

\section{References}

1. R. Shineha, Society behind the 3.11 disasters, in Science and Politics after the Disaster of March 11 in Japan, ed. by M. Nakamura, pp. 179-224 (Nakanishiya Press, Kyoto, 2013)

2. M. Tanaka, R. Shineha, K. Maruyama, Disaster Vulnerable and Information Vulnerable: What has been overlooked after the 3.11 (Chikuma Press, Tokyo, 2012)

3. Cabinet Office, White paper of disaster prevention 2011 (2011). http://www.bousai.go.jp/ kaigirep/hakusho/h23/index.htm. Accessed 30 Aug 2015

4. U. Beck, Risikogesellschaft - Auf dem Weg in eine andere Moderne. Suhrkamp Verlag (1986)

5. B. Wisner, P. Blaikie, T. Cannon, I. Davis, At Risk: Natural Hazards, People's Vulnerability and Disasters, 2nd edn. (Routledge, 2003)

6. Waseda University, Report on actual condition survey of damages of residents in the Namie-town from results of questionnaire (2015). http://www.town.namie.fukushima.jp/ uploaded/attachment/2040.pdf. Accessed 30 Aug 2015

7. A.S. Rausch, Japan's Local Newspapers: Chihōshi and Revitalization Journalism (Routledge, New York, 2012)

8. A. Downs, Up and Down with Ecology: The Issue Attention Cycle. The Public Interest no. 28, 38-51 (1972)

9. R.M. Entman, Framing: Toward Clarification of a Fractured Paradigm. Journal of Communication no. 43, 51-58 (1993)

10. M.E. McCombs, D.L. Shaw, The agenda-setting function of mass media. Public Opinion Quarterly no. 36, 176-187 (1972)

11. D.A. Scheufele, Framing as a theory of media effects. International Communication Association no. 49, 103-122 (1999)

12. K. Higuchi, Tekisutogata-data no keiryouteki bunseki: futatsu no apurochi no shunbetsu to tougou (Quantitative Analysis of Textual Data: Differentiation and Coordination of Two Approaches). Riron to Houhou (Sociological Theory and Methods) no. 19: 101-115 (2004)

13. K. Higuchi, Syakaichousa no tameno keiryou tekisuto bunseki (Quantitative Analysis for Social Researchers: A Contribution to Content Analysis) (Nakanishiya Press, Kyoto, 2014) 
14. L. Leydesdorff, I. Hellsten, Metaphors and diaphors in science communication: mapping the case of "stem-cell research". Science Communication no. 27, 64-99 (2005)

15. L. Leydesdorff, I. Hellsten, Measuring the meaning of words in contexts: an automated analysis of controversies about "monarch butterflies," "frankenfoods," and "stem cells." Scientometrics (67) 231-258 (2006)

16. W.P. Jones, G.W. Furnas, Pictures of relevance: a geometric analysis of similarity measures. Journal of the American Society for Information Science no. 36, 420-442 (1987)

17. G. Salton, A. Wong, C.S. Yang, A vector space model for automatic indexing. Information Retrieval and Language Processing 18, 613-620 (1975)

18. G. Salton, M.J. McGill, Introduction to Modern Information Retrieval (McGraw-Hill, New York, 1983)

19. V. Batagelj, A. Mrvar, Pajek: A Program for Large-Network Analysis. Connections no. 21, 47-57 (1998)

20. T. Kamada, S. Kawai, An algorithm for drawing general undirected graphs. Information Processing Letters no. 31, 7-15 (1989)

21. L.C. Freeman, Centrality in Social Networks Conceptual Clarification. Social Networks no. 1, 215-239 (1979)

22. Ministry of Internal Affairs and Communications. (2011). Report on Current Status of Information and Communications 2010 (2011). http://www.soumu.go.jp/main_content/ 000114508.pdf. Accessed 30 Aug 2015)

Open Access This chapter is licensed under the terms of the Creative Commons Attribution 4.0 International License (http://creativecommons.org/licenses/by/4.0/), which permits use, sharing, adaptation, distribution and reproduction in any medium or format, as long as you give appropriate credit to the original author(s) and the source, provide a link to the Creative Commons license and indicate if changes were made.

The images or other third party material in this chapter are included in the chapter's Creative Commons license, unless indicated otherwise in a credit line to the material. If material is not included in the chapter's Creative Commons license and your intended use is not permitted by statutory regulation or exceeds the permitted use, you will need to obtain permission directly from the copyright holder.

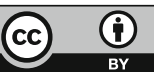

